\title{
Biofabrication of Au-Pt Nanoparticles Using Asarum europaeum Extract and Evaluation of Their Activity in Degradation of Organic Dyes
}

\author{
Renata Dobrucka ${ }^{1}$
}

Received: 8 February 2018 / Accepted: 20 April 2018 / Published online: 23 April 2018

(c) The Author(s) 2018

\begin{abstract}
Nanomaterials have attracted much attention in the recent years. The biological synthesis of metal nanoparticles is an important area of research in nanotechnology. This work describes a biological method for the synthesis of Au-Pt nanoparticles using the aqueous extract of Asarum europaeum. The synthesized Au-Pt nanoparticles were characterized by UV-Vis, scanning electron microscopy (SEM) with EDS profile, Fourier transform infrared spectroscopy (FTIR), transmission electron microscopy (TEM) and atomic force microscopy (AFM). The applied methods made it possible to determine the presence of $\mathrm{Au}-\mathrm{Pt}$ nanoparticles sized 5-6 nm. The EDS profile shows a gold and platinum signal confirming the formation of Au$\mathrm{Pt}$ nanoparticles. The synthesized $\mathrm{Au}-\mathrm{Pt}$ nanoparticles were used as a catalyst for the remediation of malachite green and methylene blue. Base on the obtained results, the $\mathrm{Au}-\mathrm{Pt}$ nanoparticles synthesized using Asarum europaeum showed good catalytic activity in the reduction of methylene blue and malachite green.
\end{abstract}

Keywords Green synthesis · Au-Pt nanoparticles · Catalytic activity

\section{Introduction}

Metal nanoparticles exhibit completely new or improved properties with larger particles of the bulk materials, and these novel properties are derived due to the variation in specific characteristics, such as size, distribution and morphology of the particles. The noble metal nanoparticles, such as gold, silver or platinum, play an important role in numerous fields of science. A great emphasis is also put on multicomponent metal nanoparticles, which are very useful in catalyst, sensor and medical applications. Multi-component metal nanoparticles usually provide novel or enhanced properties, which are not available from their individual components [1-3].

It is common knowledge that organic dyes are widely used in many branches of industry. Such dyes include malachite green oraz mehylene blue. Malachite green (MG) is a cationic dye that is widely used for the dyeing of silk, wool, jute, leather, paper, distilleries, as a food colouring agent,

Renata Dobrucka

renata.dobrucka@ue.poznan.pl

1 Department of Industrial Products Quality and Ecology, Faculty of Commodity Science, Poznan University of Economics, al. Niepodległości 10, 61-875 Poznan, Poland food additive, and in medical disinfectant and fish industries. According to Parshetti et al. [4] 10-15\% of malachite green dyes are directly lost to wastewater in the process. Methylene blue is a cationic, toxic dye which can cause mutations, allergic dermatitis, cancer, skin irritation, eye burns in humans and animals, cyanosis, methemoglobinemia, convulsions, dyspnea and tachycardia [5, 6]. It has been observed that industrial dyeing sewages strongly alter the biological, chemical and physical feature of aquatic system through perpetual variations of temperature, odor, turbidity, noise etc., which is harmful to public health, fish, livestock, wildlife, and other biodiversity as well [7].

Most synthetic dyes are very resistant to biological degradation, heat, light as well as chemical and other oxidation compounds [8]. Also, researchers are stirring and trying their best to resolve these existing problems of environmental pollution properly by sanitizing the waste contaminated water [9]. Various chemical and physical treatment methods, such as coagulation, precipitation filtration, membrane separation, electrodialysis, biological treatment, oxidation and adsorption, have been used for the removal of dyes from wastewater [10]. The photocatalytic degradation of organic as well as inorganic dyes is a promising and ambitious technology, which has a strong effect on the removal of different dyes existing in wastewater [11]. It is well-known that the 
size of metal nanoparticle plays an important role in catalytic reduction, and that nanoparticles exhibit size-dependent catalytic properties [12]. The nanostructured materials not only provide a specific surface area but also a more dispersed active site for the catalyst to provide excellent photocatalyst performance [13]. Besides, smaller nanoparticles show faster catalytic activity.

The nanoparticles of platinum and gold exhibit catalytic properties. According to the world literature, the catalytic activity of $\mathrm{Au} / \mathrm{Pt} / \mathrm{Ag}$ nanoparticles is higher than that of $\mathrm{Au}$ nanoparticles with nearly the same particle size. Also the studies conducted by Park et al. [14] demonstrated that the Pt-modified Au nanoparticles exhibited higher catalytic activity for methanol oxidation than pure Pt nanoparticles. Properties and particle size of the nano composites can be controlled by different synthesis methods $[15,16]$. There are various methods for preparing $\mathrm{Au}-\mathrm{Pt}$ nanoparticles; however, they are mainly chemical or physico-chemical. In the recent years, there has been a greater interest in the biological synthesis of nanoparticles. Researchers have tried to find biological methods for the synthesis of nanoparticles that will be an alternative to chemical or physical methods [17, 18]. Biological methods for the production of nanoparticles are considered safe and environmentally friendly; moreover, they are cost-effective and ensure the complete elimination of toxic chemicals [5].

This work used Asarum europaeum. A. europaeum is a perennial species that belongs to the Aristolochiaceae family. It grows in the fertile forests of Central and Southern Europe as well as in Siberia. The asarabacca herb contains 0.8-1\% essential oil, tannins, resin, starch, saccharose, phenolic glycosides, and sesquiterpenes. Asarabacca also contains phytoncides with strong antimicrobial properties. In the essential oil, there can be found such substances as eugenol, asaron, 1-pinen, methyl eugenol and acrolein. Due to the presence of numerous active substances, it was decided to use A. europaeum in order to obtain $\mathrm{Au}-\mathrm{Pt}$ nanoparticles.

\section{Experimental}

\subsection{Materials}

All reagents: $\mathrm{HAuCl}_{4}, \mathrm{~K}_{2} \mathrm{PtCl}_{6}$ and organic dyes were purchased from Sigma-Aldrich (Poland, Poznan). Milli-Q water was used throughout the experiment.

\subsection{Synthesis of Au-Pt Nanoparticles}

Asarum europaeum was collected from Wielkopolska region (Poland). $2 \mathrm{~g}$ of powdered A. europaeum was put into $250 \mathrm{ml}$ of an aqueous solution and ethanol in the 21 ratio. The solution was heated and stirred vigorously for $60 \mathrm{~min}$ at $85^{\circ} \mathrm{C}$.
The obtained extract was used immediately after filtration through Whatman's No. 1 filter paper. Then, solution I was prepared. In order to prepare solution I, prepared extract was mixed with $1 \mathrm{mM}$ of the aqueous solution of $\mathrm{HAuCl}_{4}$ in the $1: 1$ ratio. Next, solution II was prepared by mixing $1 \mathrm{mM}$ of $\mathrm{K}_{2} \mathrm{PtCl}_{6}$ with the extract in the 1:1 ratio. Both solutions were stirred for $12 \mathrm{~h}$ at $90{ }^{\circ} \mathrm{C}$. After that time, solutions I and II were mixed in the 1:1 ratio. The obtained solution was stirred for $24 \mathrm{~h}$ at $80^{\circ} \mathrm{C}$. The absorbance readings were made 2, 4, 8 and $24 \mathrm{~h}$ after the combination of both solutions in order to check the progress of the reaction.

\subsection{Characterization of Au-Pt Nanoparticles}

The optical property of Au-Pt nanoparticles was analyzed via ultraviolet and visible absorption spectroscopy (spectrophotometer Cary E 500) in the range $300-800 \mathrm{~nm}$. Do badania binding properties of $\mathrm{Au}-\mathrm{Pt}$ nanoparticles Fourier transform infrared spectroscopy (FTIR) analysis was used. Analysis FTIR was conducted using Perkin Elmer Spectrum 1000 , in attenuated total reflection mode and using spectral range of $4000-380 \mathrm{~cm}^{-1}$, with a resolution of $4 \mathrm{~cm}^{-1}$. The nanoparticles size was analyzed using high resolution scanning electron microscope (HR SEM) Helios NanoLab 660 (FEI) and the composition was investigated using energydispersive X-ray spectroscopy (EDX). The shape and size of the synthesized $\mathrm{Au}-\mathrm{Pt}$ nanoparticles was analyzed using a transmission electron microscope (TEM) JEOL JEM 1200 EXII operating at accelerated voltage of $80 \mathrm{keV}$. Atomic force microscopy (AFM) was conducted INTEGRA SPECTRA SOLAR of NT-MDT brand, measurement tips dedicated for NSGO1 high-resolution measurements. The resonance frequency of the tips ranged from 87 to $230 \mathrm{kHz}$. The force constant ranged from 1.45 to $15.1 \mathrm{Nm}^{-1}$, and the scanning area was $10 \mu \mathrm{m} \times 10 \mu \mathrm{m}$. Within the scanning area, there were $1000 \times 1000$ scanning points.

\subsection{Catalytic Properties of Au-Pt Nanoparticles}

The catalytic activity of Au-Pt nanoparticles was evaluated using UV-Vis spectrophotometer Cary E 500 to monitor the absorbance peaks. The absorbance was measured in the range of $450-800 \mathrm{~nm}$ at room temperature. The study of the catalytic activity of $\mathrm{Au}-\mathrm{Pt}$ nanoparticles was conducted with the use of the aqueous solution of methylene blue and malachite green $\left(1 \times 10^{-4} \mathrm{M}\right)$. Firstly, the aqueous solution of methylene blue and malachite green was monitored by measuring the absorbance intensity. In the next step, $4 \mathrm{ml}$ of methylene blue and malachite green, $0.5 \mathrm{ml}$ of A. europaeum herb water extract and $3 \mathrm{ml}$ of Milli Q water were analyzed. Then, the absorbance was measured for the solution containing $4 \mathrm{ml}$ of organic dyes $\left(1 \times 10^{-4} \mathrm{M}\right), 0.5 \mathrm{ml}$ of A. europaeum herb water extract, 
$0.5 \mathrm{ml}$ of the prepared solution of Au-Pt nanoparticles and $2.5 \mathrm{ml}$ of Milli Q water. The absorbance was measured at 5-min intervals for $30 \mathrm{~min}$. At that time, there was observed a reduction of the organic dyes: methylene blue and malachite green.

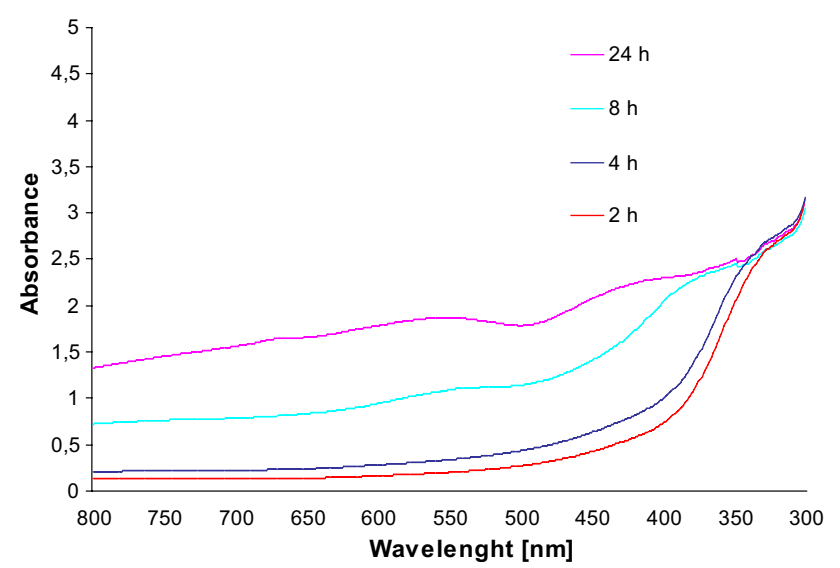

Fig. 1 UV-Visible spectra of synthesized Au-Pt nanoparticles using A. europaeum

\section{Results and Discussion}

\subsection{UV-Visible Absorption}

As it is known, UV-Vis spectroscopy is one of important techniques to determine the formation of metal nanoparticles in an aqueous solution. UV-Vis (ultraviolet and visible light) absorption spectra were measured over a range of 300-800 nm with spectrophotometer Cary E 500 using a quartz cell with $10 \mathrm{~mm}$ of optical path length. UV-Vis tool gave the absorbance of the Au-Pt nanoparticles. The absorbance was read 2, 4, 8 and $24 \mathrm{~h}$ after both solutions have been mixed. Figure 1 presents the UV-visible spectra of $\mathrm{Au}-\mathrm{Pt}$ nanoparticles synthesized using A. europaeum. After 2 and $4 \mathrm{~h}$, the peak was observed at $330 \mathrm{~nm}$; it suggested the presence of Pt ions in the examined solution. Only after $24 \mathrm{~h}$ the peak at $330 \mathrm{~nm}$ indicated the presence of $\mathrm{Pt}^{\circ}$. The peak at $550 \mathrm{~nm}$ confirmed the presence of $\mathrm{Au}^{\circ}$ in this solution.

\subsection{FTIR Analysis}

The FTIR measurement was carried out to identify the possible biomolecules responsible for the capping and efficient stabilization of the synthesized Au-Pt nanoparticles. Figure 2 presents the FTIR spectra of $\mathrm{Au}-\mathrm{Pt}$ nanoparticles synthesized using Asarum europaeum. The spectra show bands at 3312, 2121, 1634, 390, 419 and $398 \mathrm{~cm}^{-1}$. The strong

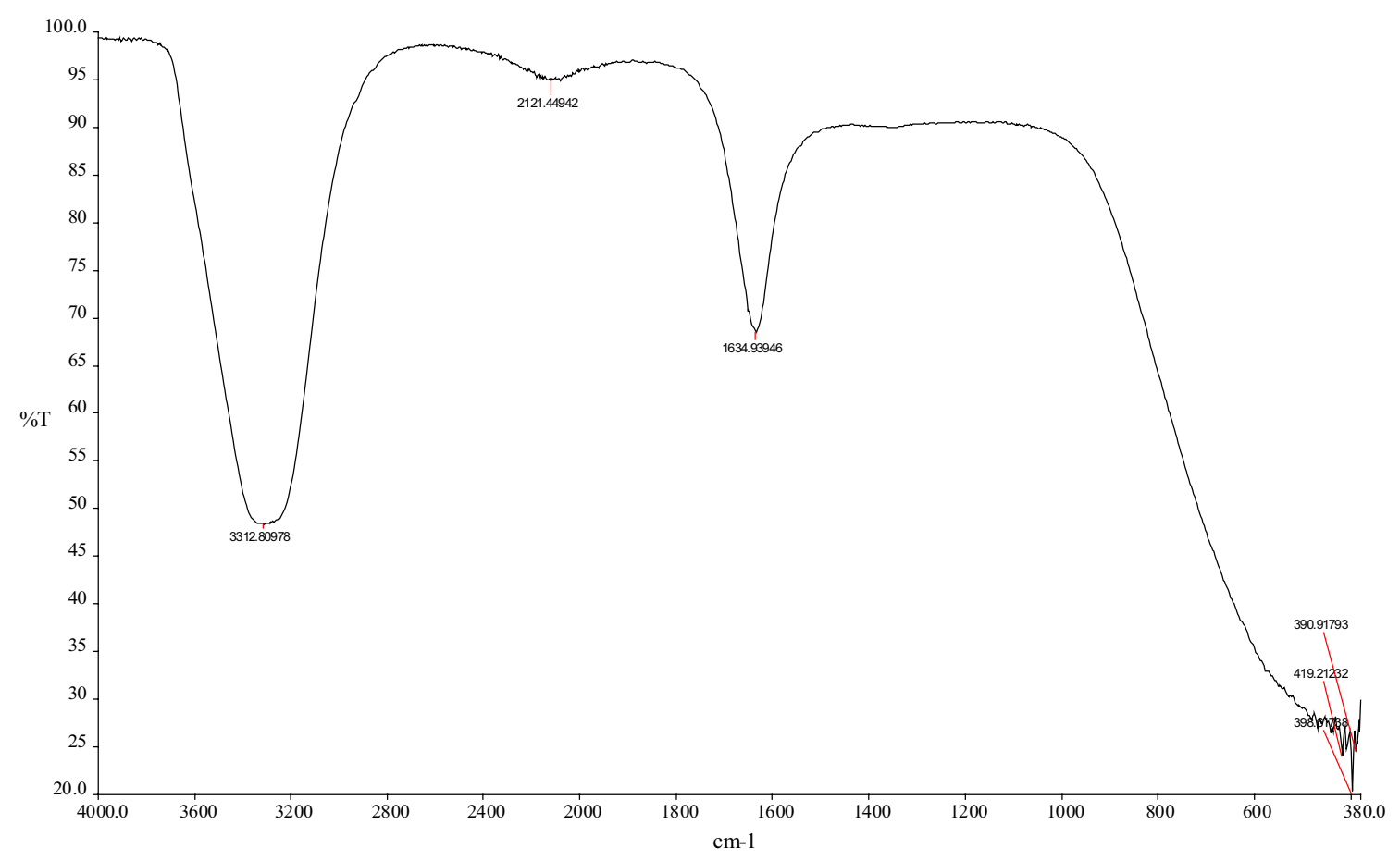

Fig. 2 FTIR spectrum of synthetised Au-Pt nanoparticles using A. europaeum 
peak at $3312 \mathrm{~cm}^{-1}$ was observed for the $\mathrm{O}-\mathrm{H}$ bond vibrations of the hydroxyl group. The band which appeared at $2121 \mathrm{~cm}^{-1}$ may indicate the presence of the alkynes group. The most intense band at $1634 \mathrm{~cm}^{-1}$ corresponds to amide bonds of proteins that may arise due to carboxyl stretching $[6,7]$. The band at 390 and $398 \mathrm{~cm}^{-1}$ is attributed to the deformation vibration of $\mathrm{C}-\mathrm{C}$ in polymer chains. The studies confirm the presence of active compounds that are found in A. europaeum. It has been assumed that the bioactive compounds act as the reducing and capping agents of $\mathrm{Au}-\mathrm{Pt}$ nanoparticles. Phenolic compounds have good antioxidant proprieties; they inhibit the production of reactive oxygen species (ROS), and thus constitute a protection against oxidative stress [8]. Moreover, the number of hydroxyl groups and their location in a phenolic acid particle are responsible for the ability to neutralize radicals and prevent oxidation by natural phenolic compounds, such as caffeic acid. In the reactions with free radicals, $-\mathrm{OH}$ groups act as hydrogen donors, which leads to the emergence of phenoxyl radical. The presence of an -OH group in the ortho position significantly influences the increase in the antioxidant properties of phenolic acids [9]. Chlorogenic acid present in A. europaeum is highly effective in inhibiting the oxidation of LDL in vitro, which is comparable with the activity of caffeic acid $[10,11]$. Figure 3 shows the chemical structure of active compounds present in A. europaeum: (A) Chlorogenic acid, (B) Caffeic acid, (C) Eugenol and (D) Asaron.

\subsection{SEM and TEM Analysis}

TEM is a well-established method for observing the sizes of nanoparticles. Figure 4 shows the TEM and SEM images of $\mathrm{Au}-\mathrm{Pt}$ nanoparticles synthesized using A. europaeum. The TEM images (Fig. 8a the scale bar: $200 \mathrm{~nm}$ and b $100 \mathrm{~nm}$ ) confirmed that the size of the synthesized $\mathrm{Au}-\mathrm{Pt}$ nanoparticles was about $5 \mathrm{~nm}$. Moreover, transmission electron microscopy (TEM) images present very small irregular nanoparticles of Au-Pt. The morphology of the synthesized Au-Pt nanoparticles was studied using scanning electron microscopy (SEM). Figure 5c, d present the SEM images of $\mathrm{Au}-\mathrm{Pt}$ nanoparticles at different magnifications (respectively $\times 50,000$ and $\times 300,000$ ). The size

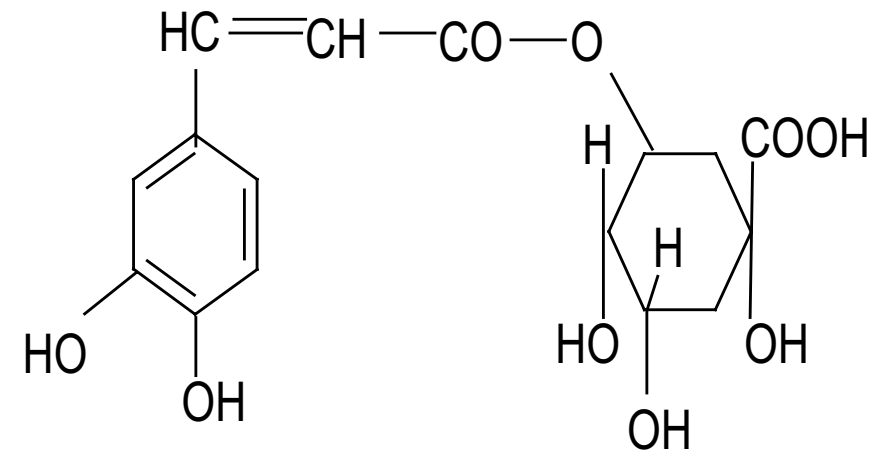

(a)

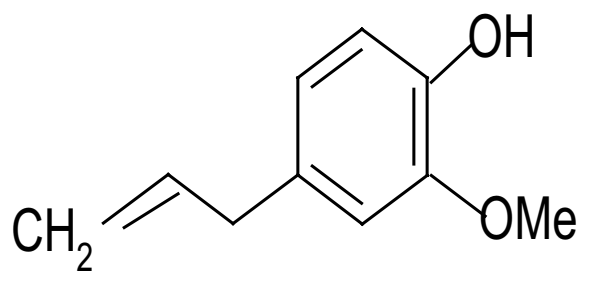

(c)

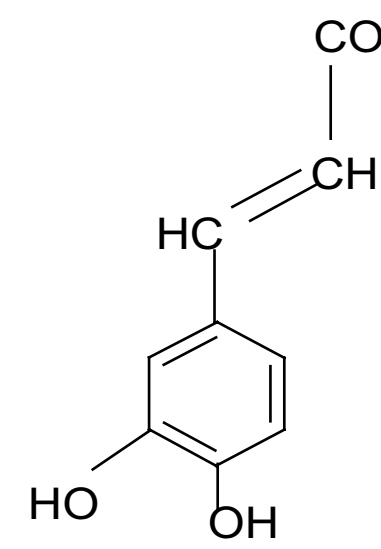

(b)

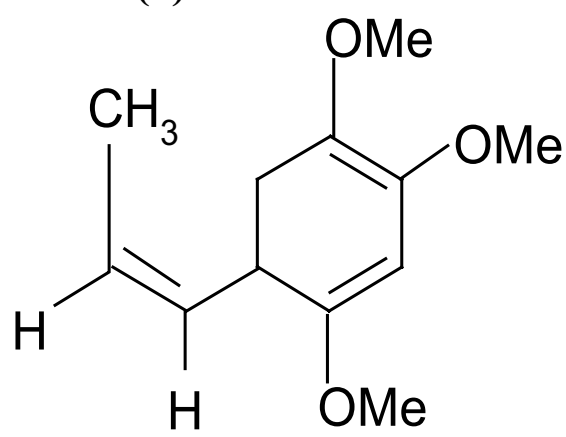

(d)

Fig. 3 The chemical structure of active compounds present in A. europaeum: a Chlorogenic acid, b Caffeic acid, c Eugenol and d Asaron 
Fig. 4 TEM and SEM images of synthesized Au-Pt nanoparticles using A. europaeum, the scale bar a $200 \mathrm{~nm}, \mathbf{b} 100 \mathrm{~nm}$, magnificaton $\mathbf{c} \times 50,000$ and $\mathbf{d}$ $\times 300,000$

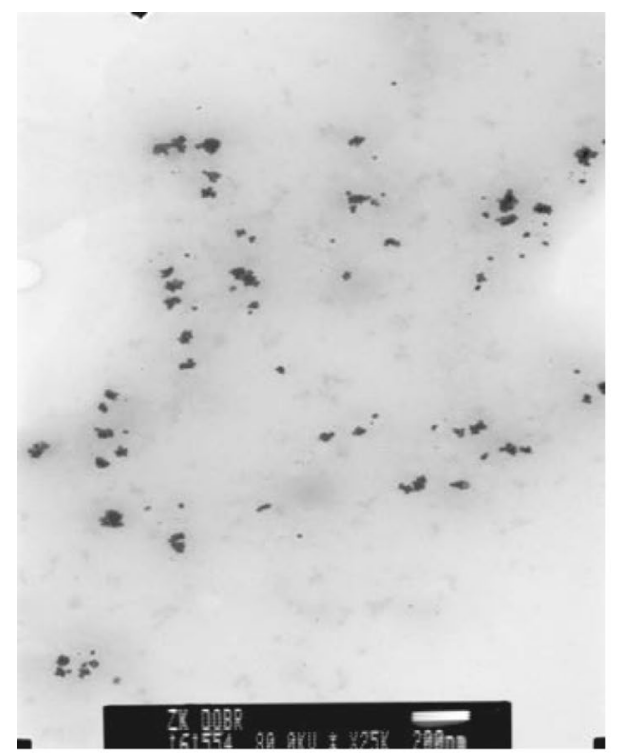

(a)

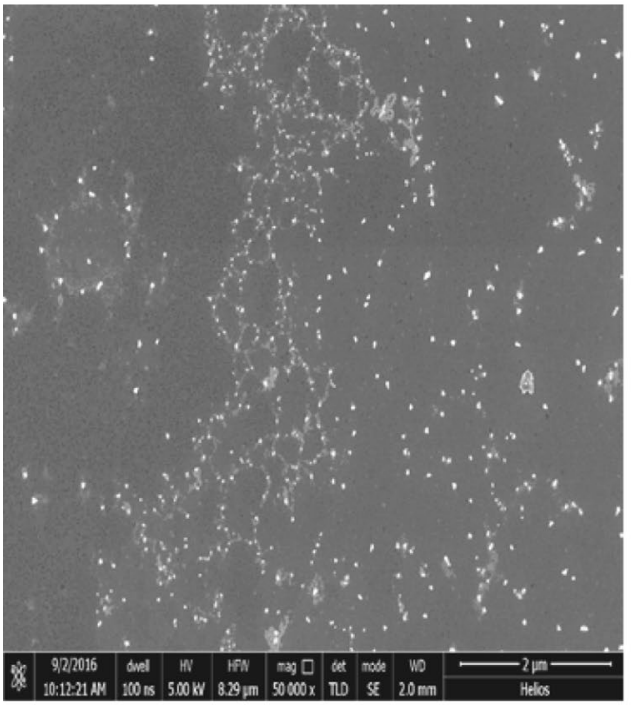

(c)

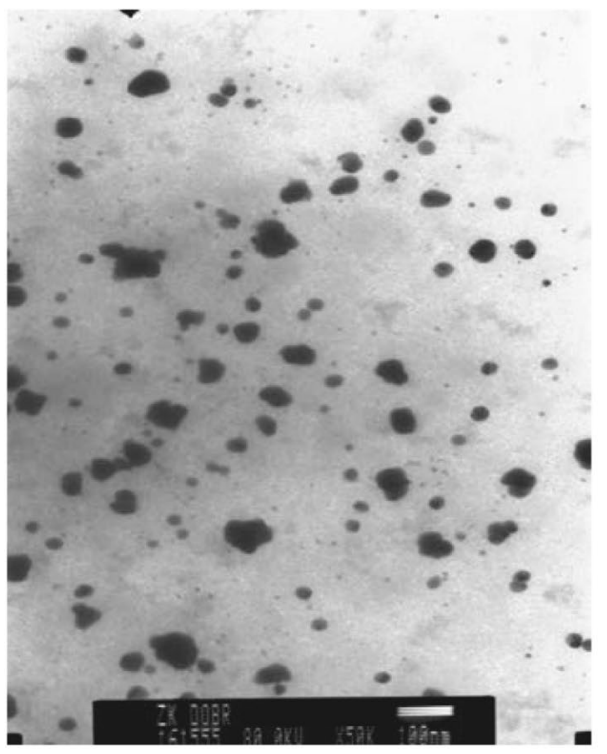

(b)

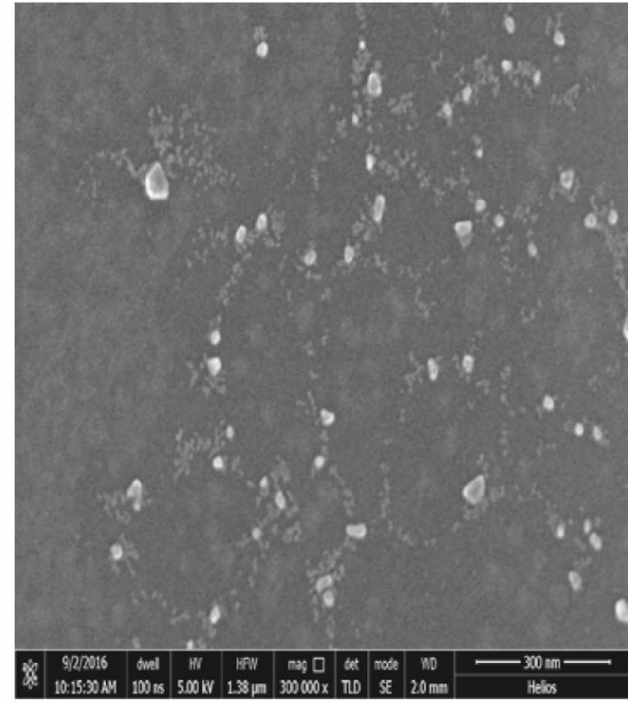

(d)

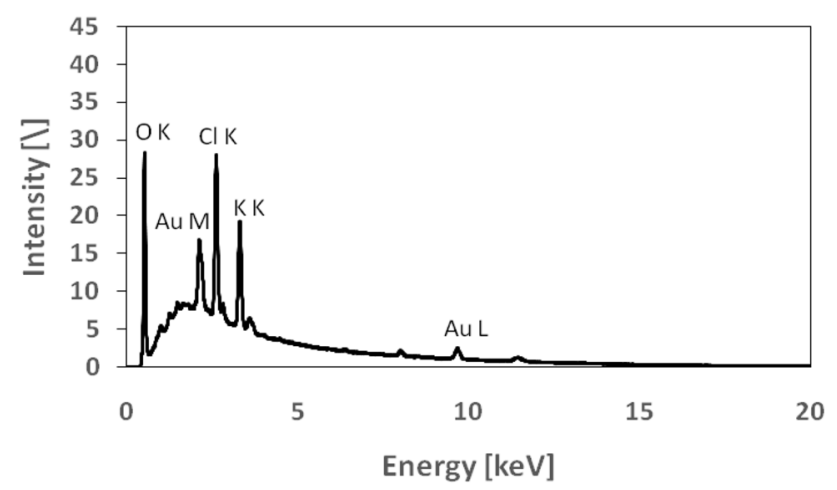

Fig. 5 EDS spectra of synthesized Au-Pt nanoparticles using A. europaeum of very small synthesized $\mathrm{Au}-\mathrm{Pt}$ nanoparticles was about 5-6 $\mathrm{nm}$. In places, the bigger nanoparticles are visible. It is a effect of places of agglomeration of nanoparticles.

\subsection{EDS Profile}

Figure 5 presents the EDS spectra of $\mathrm{Au}-\mathrm{Pt}$ nanoparticles synthesized using A. europaeum. The EDS profile shows a gold and platinum signal confirming the formation of $\mathrm{Au}-\mathrm{Pt}$ nanoparticles. The EDS profile is the additional evidence of the formation of $\mathrm{Au}-\mathrm{Pt}$ nanoparticles. 


\subsection{AFM Analysis}

The analysis of the size of the $\mathrm{Au}-\mathrm{Pt}$ nanoparticles synthesized using A.europaeum was performed by means of the atomic force microscopy (AFM). The size of the studied nanopartciles was about $5 \mathrm{~nm}$. They also showed considerable stability. This study confirmed the previous results (SEM and TEM), which also indicated that the size of the Au-Pt nanoparticles was about $5 \mathrm{~nm}$. Figure 6 shows AFM image of the synthesized Au-Pt nanoparticles using A. europaeum where: (a) the topography $10 \mu \mathrm{m} \times 10 \mu \mathrm{m}$, (b) the topography $10 \mu \mathrm{m} \times 10 \mu \mathrm{m}$ with selected section, (c) the topography $3 \mu \mathrm{m} \times 3 \mu \mathrm{m}$, (d) the topography $1.5 \mu \mathrm{m} \times 1.5 \mu \mathrm{m}$.
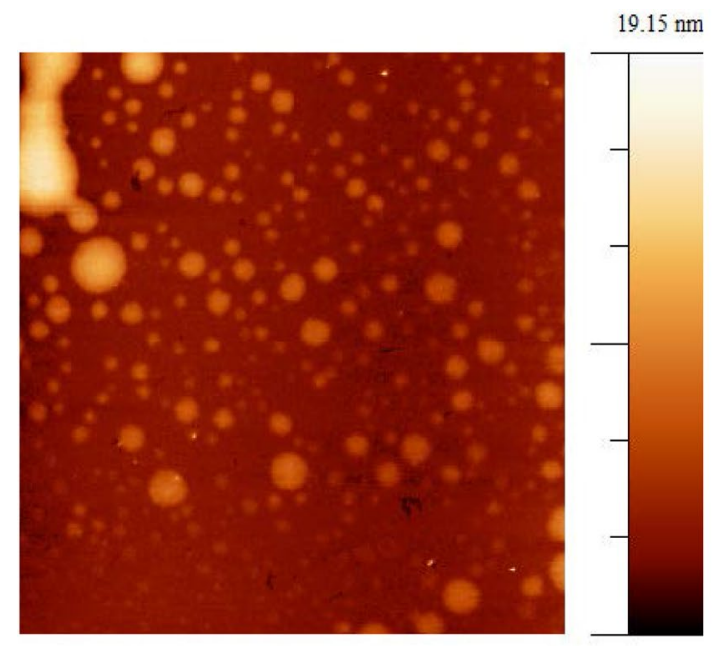

(a)

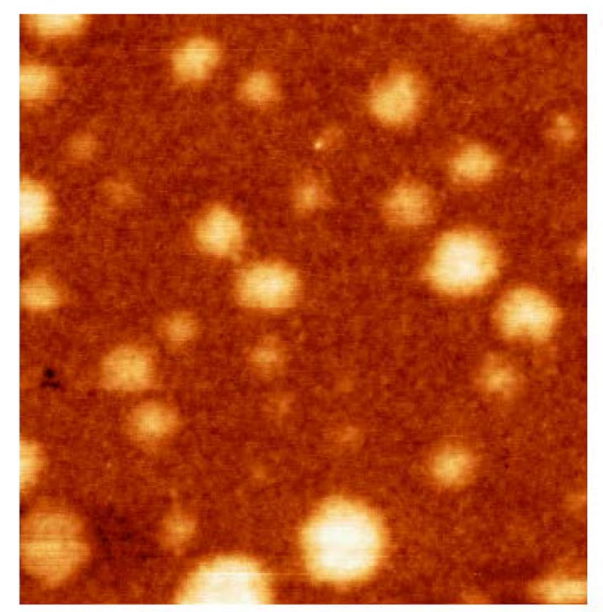

(c)

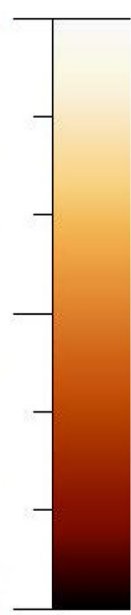

\subsection{Catalytic Activity of Au-Pt Nanoparticles}

In this work, the synthesized Au-Pt nanoparticles were used as a catalyst for the remediation of malachite green and methylene blue. The first step of the experiment was to measure the absorbance of the aqueous solutions of methylene blue and malachite green. Then, the examined dye, the aqueous solution and distilled water were mixed. The obtained solution was examined for the period from 5 to $30 \mathrm{~min}$. The absorbance was measured at 5-min intervals.

Figure 7 presents UV-Vis absorption spectra of the malachite green reduction by $\mathrm{Au}-\mathrm{Pt}$ nanoparticles synthesized using A. europaeum extract for a time period of $30 \mathrm{~min}$. The maximum absorbance value of malachite green was recorded at $615 \mathrm{~nm}$. During $30 \mathrm{~min}$ of exposure to UV-VIS

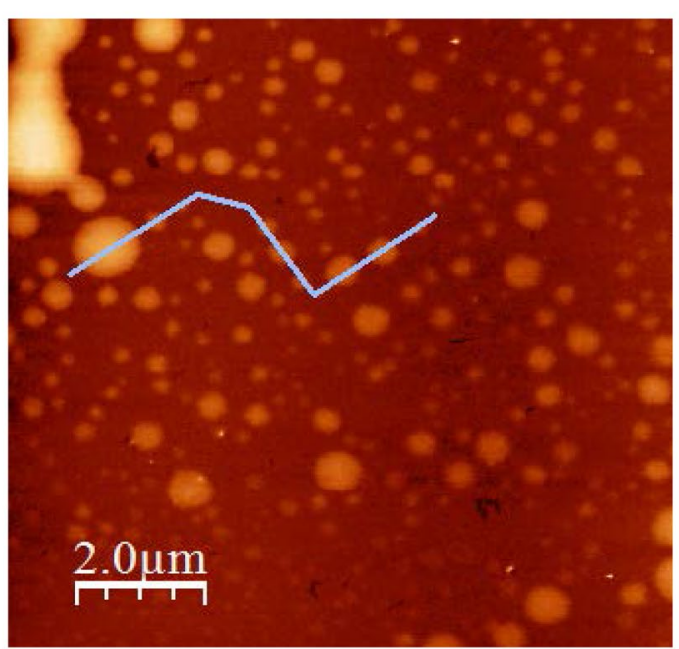

(b)
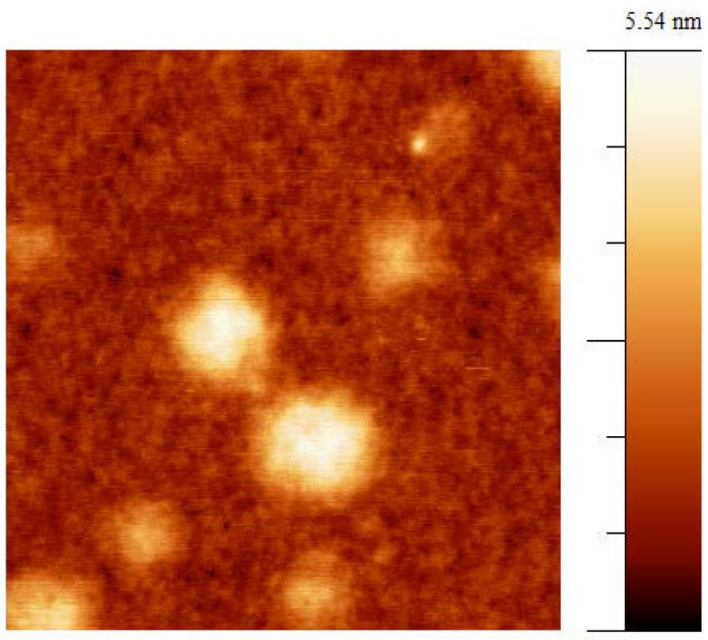

(d)

Fig. 6 AFM image of the synthesized Au-Pt nanoparticles using A. europaeum a the topography $10 \mu \mathrm{m} \times 10 \mu \mathrm{m}$, b the topography $10 \mu \mathrm{m} \times 10 \mu \mathrm{m}$ with selected section, $\mathbf{c}$ the topography $3 \mu \mathrm{m} \times 3 \mu \mathrm{m}, \mathbf{d}$ the topography $1.5 \mu \mathrm{m} \times 1.5 \mu \mathrm{m}$ 
Fig. 7 UV-Vis absorption spectra of malachite green reduction by $\mathrm{Au}-\mathrm{Pt}$ nanoparticles synthesized using A. europaeum extract. (Color figure online)

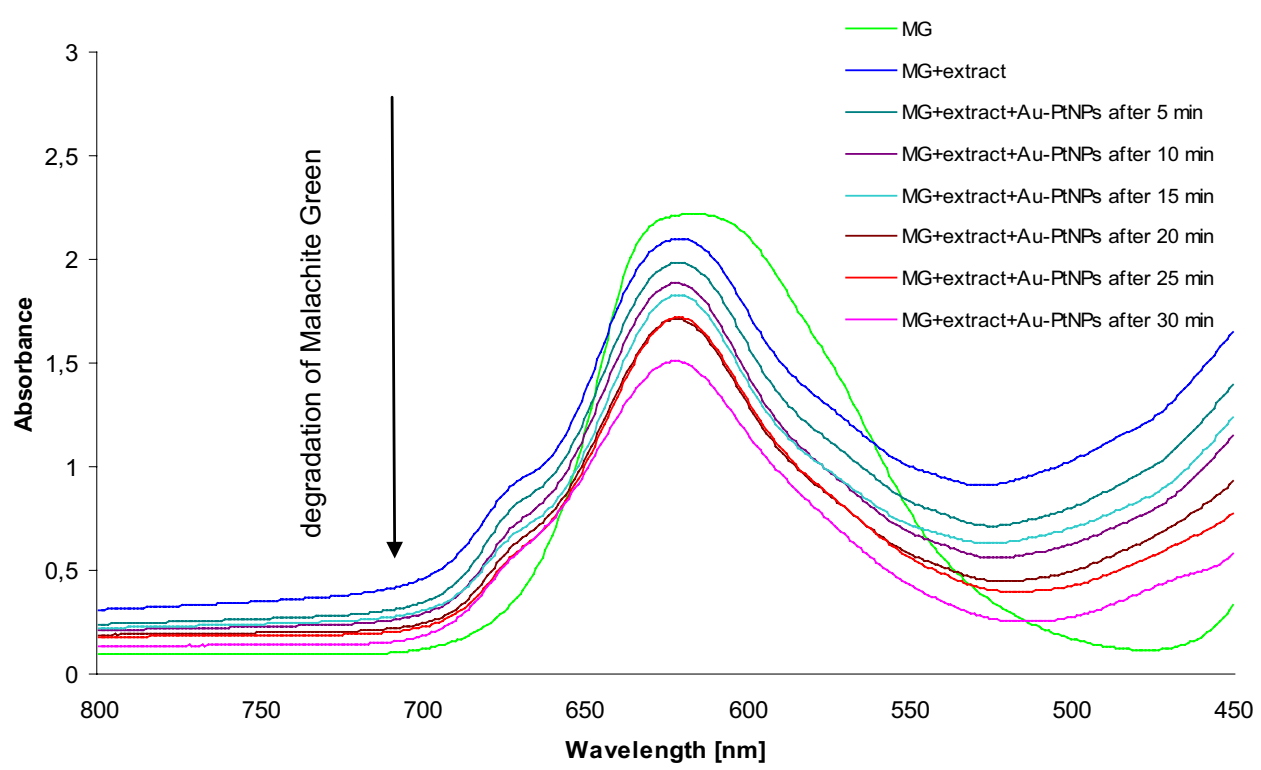

radiation, it was observed that the absorbance intensity peak of malachite green reduction decreased quickly and shifted to higher wavelength side. This diagram shows the degradation of malachite green with the use of $\mathrm{Au}-\mathrm{Pt}$ nanoparticles synthesized using A. europaeum extract.

Figure 8 shows UV-Vis absorption spectra of methylene blue reduction by $\mathrm{Au}-\mathrm{Pt}$ nanoparticles synthesized using $A$. europaeum extract for a time period of $30 \mathrm{~min}$. The degradation of methylene blue is clearly visible. The maximum absorbance value of methylene blue was recorded at $660 \mathrm{~nm}$.
After $30 \mathrm{~min}$, there was observed a significant decrease of methylene blue. In addition, the color changed from intense blue to light blue.

These studies show that $\mathrm{Au}-\mathrm{Pt}$ nanoparticles synthetized biologically, using A.europaeum, exhibited high catalytic activity. According to Aswathy Aromal et al. [19], the speed of the reduction increases when the size of nanoparticles decreases. In accordance with this theory, the small size of the obtained $\mathrm{Au}-\mathrm{Pt}$ nanoparticles contributed to their high efficiency in the reduction of organic dyes, as smaller
Fig. 8 UV-Vis absorption spectra of methylene blue reduction by $\mathrm{Au}-\mathrm{Pt}$ nanoparticles synthesized using A.europaeum extract. (Color figure online)

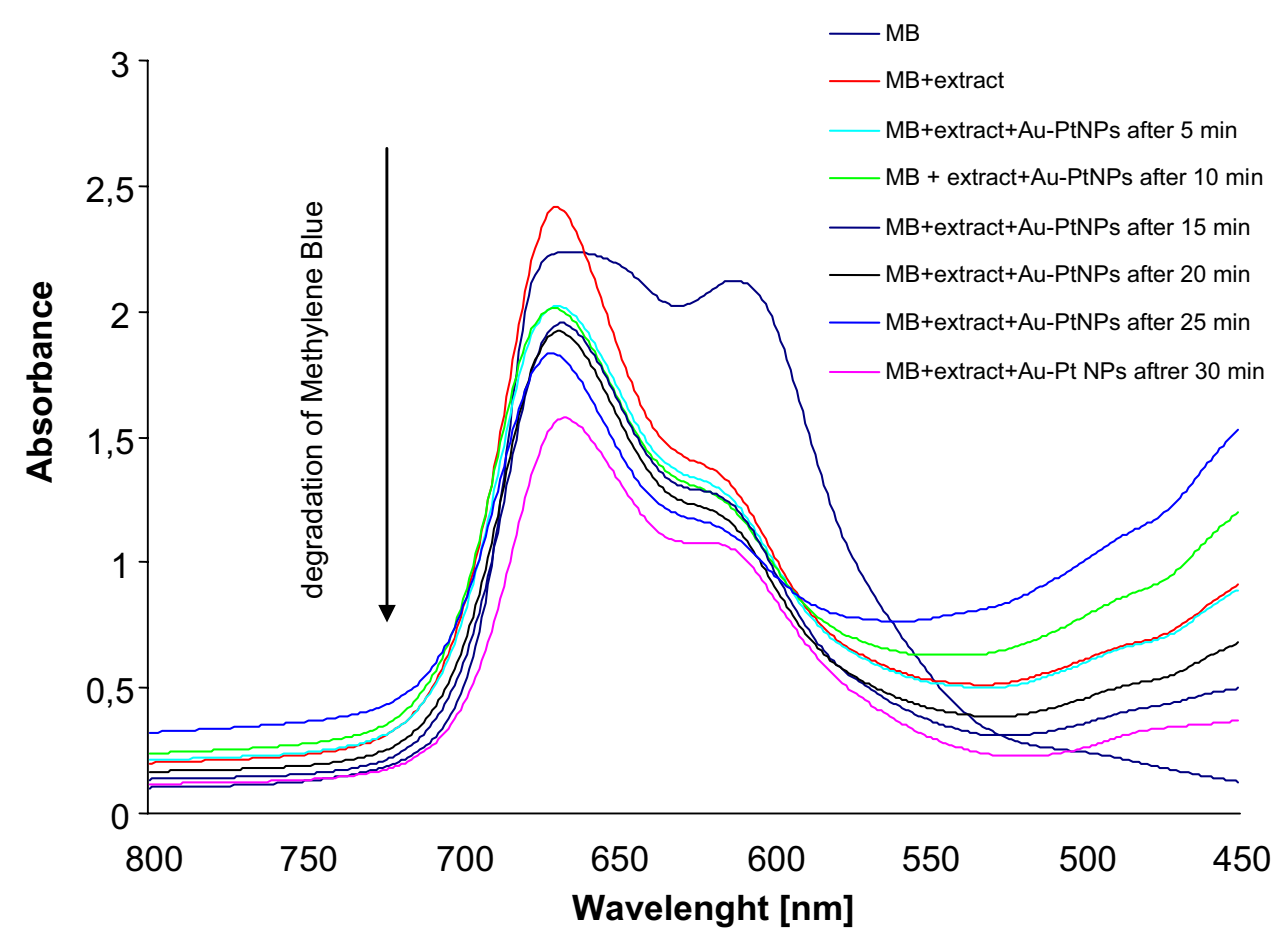


nanoparticles show faster activity. The catalytic activity of $\mathrm{Au}$ [19] or Pt [8] has been discussed by many authors. However, the multi-component nanoparticles show greater catalytic properties than individual metal nanoparticles. Zhang and Toshima reported that the catalytic activity of $\mathrm{Au} / \mathrm{Pt} / \mathrm{Ag}$ nanoparticles is higher than that of Au nanoparticles with nearly the same particle size [20].

Titanium dioxide $\left(\mathrm{TiO}_{2}\right)$ is one of the best material due to excellent properties such as nontoxicity, strong oxidizing power and stability [21]. Zhou et al. [22] showed the activity of gold supported on mesoporous $\mathrm{TiO}_{2}$ in the degradation process of Rhodamine- $\mathrm{B}$. The $\mathrm{Au}-\mathrm{TiO}_{2}$ presented the highest visible activity due to the synergistic effect of gold nanoparticles and the improved efficiency of the interfacial charge transfer proces. Hai et al. showed that titania surface modification with $\mathrm{Au}, \mathrm{Cu}$ and bimetallic $\mathrm{Au}-\mathrm{Cu}$ NPs enables the increase of the photocatalytic activity under UV-visible irradiation [23]. Tabatabaei et al. [24] found that $\mathrm{Au}-\mathrm{TiO}_{2}$ exhibited the best photocatalytic activity in the degradation of methylene blue in the presence of visible light irradiation. Reedy et al. [25] founded that the heterogeneous $\mathrm{Ag}-\mathrm{TiO}_{2}$ composite showed a higher activity than the pure $\mathrm{TiO}_{2}$ nanofiber. The enhanced activity can be attributed to the excellent distribution and interaction of $\mathrm{Ag}$ nanoparticles with the $\mathrm{TiO}_{2}$ nanofiber support also, current studies prove that the application of two components of metal nanoparticles gives great effects in the degradation of organic dyes. This is a proposal solution used in the degradation of organic dyes.

\section{Conclusion}

Metal nanoparticles have come into focus due to their wide and highly interesting properties. Green synthesized metal nanoparticles have gained considerable attention in the recent years as a result of their potential applications in various fields of science. One of such interesting applications is the degradation of dyes. This work presents the biological method for synthesizing multi-component $\mathrm{Au}-\mathrm{Pt}$ nanoparticles with the use of A. europaeum extract. The examination methods used in the work, i.e. UV-Vis, SEM, TEM, FTIR and AFM, made it possible to characterize the obtained nanoparticles in detail. The applied methods confirmed that the size of the nanoparticles was about 5-6 $\mathrm{nm}$. The EDS profile provided the additional evidence of the formation of $\mathrm{Au}-\mathrm{Pt}$ nanoparticles. The synthesized $\mathrm{Au}-\mathrm{Pt}$ nanoparticles were used as a catalyst for the remediation of malachite green and methylene blue. The catalytic activity of $\mathrm{Au}-\mathrm{Pt}$ nanoparticles was evaluated using UV-Vis spectrophotometer Cary E 500 to monitor the absorbance peaks. The absorbance was measured at 5-min intervals for $30 \mathrm{~min}$. There has been observed an efficient degradation of malachite green and methylene blue in the presence of the obtained $\mathrm{Au}-\mathrm{Pt}$ nanoparticles. The prepared $\mathrm{Au}-\mathrm{Pt}$ nanoparticles showed very good catalytic activity. This work is anticipated to open new directions in the synthesis of multicomponent $\mathrm{Au}-\mathrm{Pt}$ nanoparticles which are highly efficient in the removal of organic dyes.

Acknowledgements This work has been financed from grant for young researchers in 2016 of the Ministry of Science and Higher Education.

Open Access This article is distributed under the terms of the Creative Commons Attribution 4.0 International License (http://creativeco mmons.org/licenses/by/4.0/), which permits unrestricted use, distribution, and reproduction in any medium, provided you give appropriate credit to the original author(s) and the source, provide a link to the Creative Commons license, and indicate if changes were made.

\section{References}

1. C.J. Zhong, J. Luo, B. Fang, B.N. Wanjala, P.N. Njoki, R. Loukrakpam, J. Yin, Nanotechnology 21(6), 062001 (2010)

2. L. Feng, G. Gao, P. Huang, K. Wang, X. Wang, T. Luo, C. Zhang, Nano Biomed. Eng. 2(4), 258-267 (2010)

3. Y.P. Zhang, S.H. Lee, K.R. Reddy, A.I. Gopalan, K.P. Lee, J. Appl. Polym. Sci. 104(4), 2743-2750 (2007)

4. G. Parshetti, S. Kalme, G. Saratale, S. Govindwar, Biodegradation of malachite green by Kocuriarosea MTCC1532. Acta Chim. Slov. 53, 492-498 (2006)

5. A.M. Vargas, A.L. Cazetta, M.H. Kunita, T.L. Silva, V.C. Almeida, Chem. Eng. J. 168, 722-730 (2011)

6. M.S. Ur Rehman, I. Kim, J.I. Han, Carbohydr. Polym. 90, 1314$1322(2012)$

7. M.B. Tahir, G. Nabi, N.R. Khalid, M. Rafique, Ceram. Int. (2017). https://doi.org/10.1016/j.ceramint.2017.12.223

8. K.A. Adegoke, O.S. Bello, Dye sequestration using agricultural wastes as adsorbents. Water Resour. Ind. 12, 8-24 (2015)

9. M.B. Tahir, G. Nabi, T. Iqbal, M. Sagir, M. Rafique, Ceram. Int. (2018). https://doi.org/10.1016/j.ceramint.2018.01.081

10. S. Agarwal, I. Tyagi, V.K. Gupta, S. Mashhadi, M. Ghasemi, J. Mol. Liq. 223, 1340-1347 (2016)

11. M.B. Tahir, M. Sagir, M. Zubair, M. Rafique, I. Abbas, M. Shakil, A. Ahmed, J. Inorg. Organomet. Polym Mater. (2017). https://doi. org/10.1007/s10904-017-0771-x

12. K.R. Reddy, B.C. Sin, C.H. Yoo, W. Park, K.S. Ryu, J.S. Lee, Y. Lee, Scr. Mater. 58(11), 1010-1013 (2008)

13. M.B. Tahir, G. Nabi, N.R. Khalid, W.S. Khan, J. Inorg. Organomet. Polym Mater. (2017). https://doi.org/10.1007/s10904-017-0714-6

14. I.S. Park, K.S. Lee, D.S. Jung, H.Y. Park, Y.E. Sung, Electrochim. Acta 52, 5599 (2007)

15. M.B. Tahir, T. Iqbal, A. Hassan, S. Ghazal, J. Inorg. Organomet. Polym Mater. 27(5), 1430-1438 (2017)

16. M. Parishani, M. Nadafan, Z. Dehghani, R. Malekfar, G.H.H. Khorrami, Result Phys. 7, 3619-3623 (2017)

17. X. Deng, C.K. Chan, H. Tüysüz, ACS Appl. Mater. Interfaces 8(47), 32488-32495 (2016)

18. G. Parshetti, S. Kalme, G. Saratale, S. Govindwar, Acta Chim. Slov. 53, 492-498 (2006)

19. S.A. Aromal, K.D. Babu, D. Philip, Spectrochim. Acta A 96, 10251030 (2012)

20. H. Zhang, N. Toshima, Appl. Catal. A 400, 9 (2011)

21. N.R. Khalid, M. Liaqat, M.B. Tahir, G. Nabi, T. Iqbal, N.A. Niaz, Ceram. Int. 44(1), 546-549 (2018)

22. M. Zhou, J. Zhang, B. Cheng, H. Yu, Int. J. Photoenergy (2012). https://doi.org/10.1155/2012/532843 
23. Z. Hai, N. El Kolli, D.B. Uribe, P. Beaunier, M. José-Yacaman, J. Vigneron, H. Remita, J. Mater. Chem. A 1(36), 10829-10835 (2013)

24. S.M. Tabatabaei, M.E. Boushehri, S. Yavari, J. Basic Appl. Sci. Res. 2(8), 7459-7465 (2012)
25. K.R. Reddy, K. Nakata, T. Ochiai, T. Murakami, D.A. Tryk, A. Fujishima, J. Nanosci. Nanotechnol. 11(4), 3692-3695 (2011) 